\title{
Augmentation of antimicrobial activity of conventional antibiotics by cell-free extract of $L$. plantarum
}

\author{
Aman Preet Singh, Simran Preet and Praveen Rishi
}

The Journal of Antibiotics (2011) 64, 795-798; doi:10.1038/ja.2011.92; published online 19 October 2011

Keywords: cell-free extract; fractional inhibitory concentration index; MIC; probiotics; synergy

Salmonella infections represent a major health hazard and have been responsible for a number of epidemics. Antibiotics have been the mainstay of therapy to combat these infections. However, the frequent and indiscriminate use of antibiotics has led to the development of multi drug resistant (MDR) Salmonella strains showing increased MICs to various first, second and third line antibiotics. ${ }^{1}$ It necessitates the exploitation of alternative antimicrobial therapies. Combinations of antibacterial agents have been reported to be useful in overcoming resistance. In this context, probiotic and antibiotic combinatorial therapy may provide higher antimicrobial activity and also reduce the dose of antibiotic required in addition to replenishing the intestinal flora thereby providing benefit to the host. ${ }^{2}$

Probiotics are dietary supplements containing potentially beneficial bacteria or yeasts. According to the currently adopted definition by FAO/WHO in 2001, probiotics are live microorganisms, which when administered in adequate amounts confer a health benefit on the host.' ${ }^{3,4}$ For the protection against enteropathogens infections, the possibility of using food supplements containing probiotic bacteria has been recently considered. Probiotics in combination with antibiotic treatment have been reported to be successful in the management of Helicobacter pylori infection. ${ }^{5}$

Therefore, the present study was designed to assess whether the cell-free extract of Lactobacillus plantarum has the potential to augment the activity of conventional anti-Salmonella antibiotics; that is, ampicillin, ciprofloxacin, ceftriaxone against Salmonella typhimurium.

L. plantarum MTCC 2621 was procured from Institute of Microbial Technology (IMTECH), Chandigarh, India. This strain was selected on the basis of its antimicrobial activity against $S$. typhimurium as indicated from our previous studies. ${ }^{6}$ Salmonella enterica serovar Typhimurium NCTC74 initially procured from the Central Research Institute (CRI), Kasauli, India. Ampicillin, ciprofloxacin and ceftriaxone powder were procured from Sigma (St Louis, MO, USA). Antibiotic powders were dissolved at a maximum concentration of $1 \mathrm{mg} \mathrm{ml}^{-1}$ in distilled water.

Keeping in view the application of probiotics to be used in conjunction with an antibiotic, the first criteria, which a probiotic strain needs to fulfill, is that it should be resistant to that particular antibiotic to avoid direct killing of the probiotic strain. Therefore, first of all L. plantarum was tested for its susceptibility to the antibiotics by the method of Bauer et al. ${ }^{7}$ The antibiogram pattern indicated that L. plantarum was resistant to ampicillin, ciprofloxacin and ceftriaxone. This antibiogram pattern was further confirmed by agar-WDA. ${ }^{8} 10^{7}$ CFUs of L. plantarum was spread plated on DeMan-Rogosa-Sharpe (MRS) agar plates. Wells of $5 \mathrm{~mm}$ diameter were punched in the agar plates and filled with $20 \mu \mathrm{l}$ stock solution of each antibiotic $\left(1 \mathrm{mg} \mathrm{ml}^{-1}\right)$; that is, ampicillin, ciprofloxacin and ceftriaxone, respectively. The plates were then incubated at $37^{\circ} \mathrm{C}$ for $24 \mathrm{~h}$. Complete resistance was exhibited by $L$. plantarum to all three of the tested antibiotics as no inhibition of growth was observed around the wells in any plate. Thus, both of these tests indicated the feasibility of using L. plantarum in conjunction with ampicillin, ciprofloxacin and ceftriaxone.

Cell-free supernatant (CFS) from L. plantarum was prepared by the method as described by Ogunbanwo et al. ${ }^{9}$ Briefly, the strain was propagated in 11 MRS broth ( $\mathrm{pH} 6.5$ ) for $24 \mathrm{~h}$ at $37^{\circ} \mathrm{C}$. CFS was obtained by centrifuging the culture at 10000 r.p.m. for $20 \mathrm{~min}$ at $4{ }^{\circ} \mathrm{C}$ and was filtered through $0.22 \mu \mathrm{m}$ pore size cellulose acetate filter.

The MIC of the cell-free extract was estimated to be $640 \mathrm{AU} \mathrm{m}^{-1}$, thereby confirming our earlier report. ${ }^{6}$ The sensitivity of Salmonella to each of the three antibiotics was also checked and MICs were determined by broth-dilution technique. In brief, $10^{7}$ cells of S. typhimurium were grown individually in the presence of different concentrations $\left(0.03-64 \mu \mathrm{g} \mathrm{ml}^{-1}\right)$ of ampicillin, ciprofloxacin and ceftriaxone in three different 96 -well microtitre plates at $37^{\circ} \mathrm{C}$ for $24 \mathrm{~h}$. OD was measured at $620 \mathrm{~nm}$ using an enzyme-linked immunosorbent assay reader and the MIC was defined as the lowest concentration of each antibiotic not producing any visible microbial growth. The MICs of ampicillin, ciprofloxacin and ceftriaxone were evaluated to be $1 \mu \mathrm{g} \mathrm{ml}^{-1}, 6 \mu \mathrm{g} \mathrm{ml}^{-1}$ and $12 \mu \mathrm{g} \mathrm{ml}^{-1}$, respectively. However, according to NCCLS guidelines, $S$ typhimurium was classified as resistant to ceftriaxone and ciprofloxacin, and susceptible to ampicillin 
as per the MIC breakpoints ${ }^{10}$ (for ciprofloxacin and ceftriaxone susceptible $(\leqslant 1)$, intermediate $(1-4)$ and resistant $(\geqslant 4)$, for ampicillin susceptible $(\leqslant 8)$, intermediate $(8-32)$ and resistant $(\geqslant 32)$ ).

To evaluate synergy, the fractional inhibitory concentration (FIC) index was determined by checkerboard microtitre test at 64 different combinations. Briefly eight two-fold serial dilutions of each antibiotic and CFS were mixed in checkerboard fashion in a microtitre plate so that each row (and column) contained a fixed amount of one agent and increasing amount of second agent. Concentrations ranging from 0 to 2 MIC were used. The FIC index, obtained by adding both FIC, was interpreted as indicating a synergistic effect when it was $\leqslant 0.5$, as additive or indifferent when it was $>0.5$ and $\leqslant 2.0$, and as antagonistic when it was >2.0. ${ }^{11}$ The MIC values and FIC index of ampicillin, ciprofloxacin and ceftriaxone and CFS are summarized in Table 1. The synergistic anti-Salmonella activity of all these combinations was evidenced by the FIC index, which was calculated to be $<0.5$ in all the three combinations tested (Table 1).

The in-vitro synergy as estimated by checkerboard technique was further confirmed by time-kill assay using lower concentrations of each agent in combination. Briefly, ampicillin $\left(1 \mu \mathrm{g} \mathrm{ml}^{-1}\right)$, ciprofloxacin $\left(6 \mu \mathrm{g} \mathrm{ml}^{-1}\right)$, ceftriaxone $\left(12 \mu \mathrm{g} \mathrm{ml}^{-1}\right)$ and CFS $\left(640 \mathrm{AU} \mathrm{ml}^{-1}\right)$ alone and their combination, that is, CFS $\left(80 \mathrm{AU} \mathrm{m}^{-1}\right)+$ ampicillin $\left(0.063 \mu \mathrm{g} \mathrm{ml}^{-1}\right)$, CFS $\left(80 \mathrm{AU} \mathrm{ml}^{-1}\right)+$ ciprofloxacin $\left(0.75 \mu \mathrm{g} \mathrm{ml}^{-1}\right)$ and CFS $\left(160 \mathrm{AU} \mathrm{ml}^{-1}\right)+$ ceftriaxone $\left(1.5 \mu \mathrm{g} \mathrm{ml}^{-1}\right)$, were added to different $20 \mathrm{ml}$ nutrient broth flasks containing $10^{6}$ CFUs of S. typhimurium and incubated at $37^{\circ} \mathrm{C} .100 \mu \mathrm{l}$ aliquots were withdrawn at $0 \mathrm{~h}, 2 \mathrm{~h}, 4 \mathrm{~h}$, $6 \mathrm{~h}$ and $8 \mathrm{~h}$, and spread plated on MacConkey agar plates. The plates were incubated at $37^{\circ} \mathrm{C}$ for $24 \mathrm{~h}$ for enumeration of CFUs. When used alone, ampicillin $\left(1 \mu \mathrm{g} \mathrm{ml}^{-1}\right)$ and ciprofloxacin $\left(6 \mu \mathrm{g} \mathrm{ml}^{-1}\right)$ could

Table 1 MIC values and FIC index of various antimicrobial agents alone and in combinations against $S$. typhimurium as determined by Broth dilution tehnique and checkerboard method

\begin{tabular}{|c|c|c|c|c|c|c|}
\hline \multirow[b]{2}{*}{ Antimicrobial agents } & \multirow[b]{2}{*}{$M I C$} & \multicolumn{2}{|c|}{ MIC in combination } & \multicolumn{2}{|c|}{$F I C$} & \multirow[b]{2}{*}{ FIC Index } \\
\hline & & $\begin{array}{c}C F S \\
\left(A \cup m l^{-1}\right)\end{array}$ & $\begin{array}{l}\text { Antibiotic } \\
\left(\mu g \mathrm{ml}^{-1}\right)\end{array}$ & CFS & Antibiotic & \\
\hline CFS $\left(\mathrm{AU} \mathrm{ml^{-1 }}\right)$ & 640 & - & - & - & - & - \\
\hline Ampicillin $\left(\mu \mathrm{g} \mathrm{ml} \mathrm{l}^{-1}\right)$ & 1 & 80 & 0.063 & 0.125 & 0.063 & 0.19 \\
\hline Ciprofloxacin $\left(\mu g \mathrm{ml}^{-1}\right)$ & 6 & 80 & 0.75 & 0.125 & 0.125 & 0.25 \\
\hline Ceftriaxone $\left(\mu \mathrm{gml}^{-1}\right)$ & 12 & 160 & 1.5 & 0.25 & 0.125 & 0.375 \\
\hline
\end{tabular}

Abbreviations: CFS, cell-free supernatant; FIC, fractional inhibitory concentration. decrease the CFUs by 5.77 and $5.32 \log$ units, respectively after $8 \mathrm{~h}$ as compared with control. However, when used in combination with CFS $\left(80 \mathrm{AU} \mathrm{ml}^{-1}\right)$ at much lower concentrations, that is, ampicillin $\left(0.063 \mu \mathrm{g} \mathrm{ml}^{-1}\right)$ and ciprofloxacin $\left(0.75 \mu \mathrm{g} \mathrm{ml}^{-1}\right)$, a decrease of 6.44 $\log$ units and $6.27 \mathrm{log}$ units was observed, respectively. Similarly ceftriaxone $\left(12 \mu \mathrm{g} \mathrm{ml}^{-1}\right)$ alone gave a decrease of $5.40 \mathrm{log}$ units, but when used in combination with CFS $\left(160 \mathrm{AU} \mathrm{ml}^{-1}\right)$ at a much lower concentration $\left(1.5 \mu \mathrm{g} \mathrm{ml}^{-1}\right)$, a decrease of $5.64 \log$ unit was observed. The results exhibited synergy among all the combinations tested as the dose required to give the same antibacterial effect in terms of CFUs was significantly reduced as compared with when the agents were used separately at higher doses (Figure 1).

The magnitude of in-vitro synergism observed between CFS and ampicillin prompted us to further investigate the ex-vivo synergistic efficacy in terms of macrophage functions keeping in view the intracellular survival ability of Salmonella. Murine peritoneal macrophages were isolated by the method as described by us earlier ${ }^{6}$ and infected with $S$. typhimurium at a multiplicity of infection of 1:100. Intracellular killing of $S$. typhimurium was assessed when treated with MIC of both; that is, CFS $\left(640 \mathrm{AU} \mathrm{ml}^{-1}\right)$ and ampicillin $\left(1 \mu \mathrm{g} \mathrm{ml}^{-1}\right)$ separately and in combination as per FICs; that is (CFS $\left(80 \mathrm{AU} \mathrm{ml}^{-1}\right)$ + ampicillin $\left(0.063 \mu \mathrm{g} \mathrm{ml}^{-1}\right)$. After every 30, 60 and $90 \mathrm{~min}$ of treatment period, treated and untreated macrophages were pelleted (2000 r.p.m., $10 \mathrm{~min}$ ) and lysed with $500 \mu \mathrm{l}$ of $0.25 \%$ TritonX-100. Lysates were serially diluted and plated on MacConkey agar medium. After an incubation of $24 \mathrm{~h}$ at $37^{\circ} \mathrm{C}$, CFUs were counted. ${ }^{6}$ The data were analyzed using one-way analysis of variance followed by pair wise comparison procedures (Tukey test) using Jandel Sigma Stat Statistical Software, version 2.0 (Jandel SigmaStat, Jandel, San Rafael, CA, USA). The mean percentage of intracellular killing in the presence of CFS alone at 30,60 and $90 \mathrm{~min}$ was $17.39 \% \pm 6.52,29.34 \% \pm 3.81$ and $50 \% \pm 9.24$, respectively. Similarly, when infected macrophages were treated with ampicillin alone, the mean intracellular killing was $21.73 \% \pm 4.34, \quad 33.69 \% \pm 6.18$ and $53.26 \% \pm 9.78$ at 30,60 and $90 \mathrm{~min}$, respectively. A higher intracellular killing was observed when infected macrophages were treated with ampicillin in conjunction with CFS. In this case, the killing was found to be $30.43 \% \pm 4.98$ $(P<0.05)$, 54.34\% $\pm 7.07(P<0.01)$ and $83.70 \% \pm 4.34(P<0.001)$ at 30,60 and $90 \mathrm{~min}$, respectively. On the other hand, the intracellular killing in untreated macrophages was $15.22 \% \pm 2.81,26.08 \% \pm 5.26$ and $45.65 \% \pm 3.33$ at 30,60 and $90 \mathrm{~min}$, respectively (Table 2 ). The results indicate that both CFS and ampicillin might act in conjunction leading to an enhanced killing of intracellular S. typhimurium.

Earlier, chloramphenicol, ampicillin and cotrimoxazole were used to treat Salmonella infections. Later on with the emergence of MDR

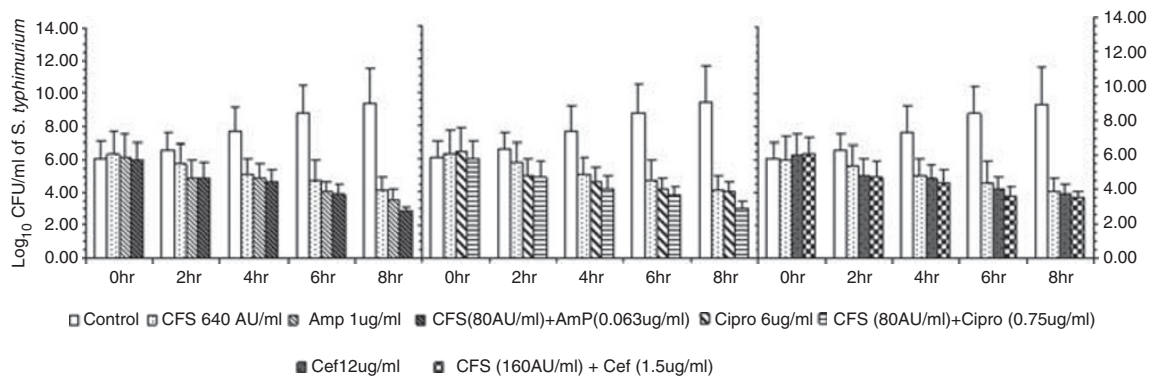

Figure 1 Time-kill assay. $\log _{10}$ CFU of Salmonella typhimurium NCTC74 at various time intervals in presence of ampicillin $\left(1 \mu \mathrm{gml} \mathrm{m}^{-1}\right)$, ciprofloxacin $\left(6 \mu \mathrm{g} \mathrm{ml}^{-1}\right)$, ceftriaxone $\left(12 \mu \mathrm{g} \mathrm{ml} \mathrm{l}^{-1}\right)$ and CFS $\left(640 \mathrm{AU} \mathrm{ml}^{-1}\right)$ alone and their combination; that is, CFS $\left(80 \mathrm{AU} \mathrm{ml} \mathrm{l}^{-1}\right)+\mathrm{ampicillin}\left(0.063 \mu \mathrm{gml} \mathrm{m}^{-1}\right), \mathrm{CFS}^{-1}$ $\left(80 \mathrm{AU} \mathrm{ml}^{-1}\right)+$ ciprofloxacin $\left(0.75 \mu \mathrm{g} \mathrm{ml}^{-1}\right)$ and CFS $\left(160 \mathrm{AU} \mathrm{ml}^{-1}\right)+$ ceftriaxone $\left(1.5 \mu \mathrm{gl}^{-1}\right)$.Values are expressed as mean $\pm \mathrm{s}$.d. of three individual values. (Synergy is evident among all the combinations tested as the dose required to give the same antibacterial effect in terms of CFUs is significantly reduced as compared with when the agents are being used separately at higher doses). 
Table 2 Effect of ampicillin and CFS on intracellular killing of Salmonella typhimurium (assessed by isolating murine peritoneal macrophages from BALB/c mice and interacting them with Salmonella in presence of CFS and ampicillin separately and in combination)

\begin{tabular}{|c|c|c|c|c|c|c|c|c|}
\hline \multirow{3}{*}{$\begin{array}{l}\text { Duration of intra- } \\
\text { cellular incubation (min) }\end{array}$} & \multicolumn{4}{|c|}{ CFU of S. typhimurium (mean \pm s.d.) $\left(\mathrm{N}_{t}\right)\left(C F U \times 10^{9}\right)$} & \multicolumn{4}{|c|}{ Mean percentage intracellular killing $\left\{\left(\mathrm{N}_{0}-\mathrm{N}_{t}-\mathrm{N}_{0}\right) \times 100\right\}$ (\%) } \\
\hline & \multirow[b]{2}{*}{ Untreated macrophages } & \multicolumn{3}{|c|}{ Treated macrophages } & \multirow[b]{2}{*}{ Untreated macrophages } & \multicolumn{3}{|c|}{ Treated macrophages } \\
\hline & & Ampi & CFS & $A m p i+C F S$ & & Ampi & CFS & $A m p i+C F S$ \\
\hline $0\left(N_{0}\right)$ & $9.2 \pm 0.9$ & - & - & - & & - & - & - \\
\hline 30 & $7.8 \pm 0.5$ & $7.2 \pm 0.4$ & $7.6 \pm 0.6$ & $6.4 \pm 0.45$ & $15.22 \pm 2.81$ & $21.73 \pm 4.34$ & $17.39 \pm 6.52$ & $30.43 \pm 4.98^{a}$ \\
\hline 60 & $6.8 \pm 1.15$ & $6.1 \pm 0.56$ & $6.5 \pm 0.35$ & $4.2 \pm 0.65$ & $26.08 \pm 5.26$ & $33.69 \pm 6.18$ & $29.34 \pm 3.81$ & $54.34 \pm 7.07^{b}$ \\
\hline 90 & $5 \pm 0.81$ & $4.3 \pm 0.9$ & $4.6 \pm 0.85$ & $1.5 \pm 0.4$ & $45.65 \pm 3.33$ & $53.26 \pm 9.78$ & $50 \pm 9.24$ & $83.70 \pm 4.34^{c}$ \\
\hline
\end{tabular}

Abbreviation: CFS, cell-free supernatant.

Values are expressed as mean \pm s.d. of three individual experiments.

a $P<0.05$, versus \% intracellular killing of $S$. typhimurium in untreated macrophages after $30 \mathrm{~min}$.

$\mathrm{b} P<0.01$, versus \% intracellular killing of $S$. typhimurium in untreated macrophages after $60 \mathrm{~min}$.

${ }^{c} P<0.001$, versus \% intracellular killing of $S$. typhimurium in untreated macrophages after $90 \mathrm{~min}$.

Salmonella strains, ciprofloxacin became the drug of choice. However, reports of increasing MIC values suggest that ciprofloxacin therapy will not remain effective for much longer. ${ }^{12-14}$ The results of current study exhibited that CFS from $L$. plantarum has the potential to augment the activity of conventional anti-Salmonella antibiotics as all these three combinations could reduce Salmonella growth significantly. This synergism provides an additional therapeutic choice by allowing the use of conventional antibiotics in conjunction with natural antibiotics against MDR Salmonella.

Ampicillin and ceftriaxone, both are $\beta$-lactam antibiotics and known to interfere with and inhibit bacterial cell wall synthesis. ${ }^{15}$ CFS contains several antimicrobials, ${ }^{16}$ lactic and non-lactic acids as well as hydrogen peroxide. It has also been reported that these acids possess bactericidal activity. They can permeate cell membrane by diffusion causing dissipation of membrane proton potential. ${ }^{17}$ Synergy between ampicillin/ceftriaxone and CFS could be attributed to the fact that the organic acids present in CFS might have helped increase permeabilization of these antibiotics to the bacterial cell membrane, thereby leading to increased antimicrobial activity.

Ciprofloxacin is a fluoroquinolone, which interferes with the DNA gyrase and inhibits DNA synthesis. CFS from $L$. plantarum has been reported to contain plantaricin (an antimicrobial peptide of $3.5 \mathrm{kDa}$ ) as well. Plantaricin is a pore-forming bacteriocin that acts on permeability barrier of cytoplasmic membrane. ${ }^{18}$ The observed synergy might be attributed to the fact that bacteriocin makes pores in the cell membranes, which allows increased amounts of ciprofloxacin to enter the cell and block DNA synthesis. Moreover, quinolones have also been reported to sensitize Gram-negative bacteria to cationic antimicrobial peptides by displacement of divalent cations from their LPS-binding sites thereby increases the binding of antimicrobial peptides to outer membrane. ${ }^{19}$ These two mechanisms might have acted mutually leading to enhanced anti-Salmonella effect of this combination.

The most potent combination was found to be that of CFS and ampicillin in terms of FIC index and time-kill assay. It can be hypothesized that CFS may contain compounds capable of inhibiting ampicillin inactivating enzymes such as $\beta$-lactamase, thereby making this very combination to be the most effective amongst all the combinations tested. Moreover, the combination also exhibited significant level of killing of Salmonella as per the ex-vivo macrophage study. This observation is in concordance with the earlier reports wherein it was proposed that ampicillin kills intracellular Salmonella within the mouse macrophages owing to its internalization by cells through pinocytosis. ${ }^{20}$ Studies have also shown that CFSs and/or extracts from lactic acid producing bacteria may activate macrophages in-vitro thereby resulting in augmented phagocytic activity. ${ }^{21,22}$ These findings can prove to be vital in rejuvenation of ampicillin therapy against Salmonella, as it is no longer used because of worldwide emergence of ampicillin-resistant Salmonella strains.

In conclusion, these combinations demonstrated excellent synergistic in-vitro potency against $S$. typhimurium. This study points towards the fact that CFS has the potential to augment the activity of the antibiotics at much lower MICs thereby rendering $S$ typhimurium sensitive to ciprofloxacin and ceftriaxone, which was earlier observed to be resistant as per the NCCLS guidelines. ${ }^{10}$ Although the observations of the present study indicate that CFS has the potential to augment the efficacy of antibiotics but the possibility of transfer of resistance genes from L. plantarum (if given as such) to Salmonella cannot be ruled out as has been reported in case of other microorganisms. ${ }^{23,24}$ This issue needs to be explored further in reference to Salmonella infections.

\section{ACKNOWLEDGEMENTS}

The authors wish to acknowledge the Council of Scientific and Industrial Research, New Delhi, for providing financial assistance to carry out this work.

1 Birosova, L. \& Mikulasova, M. Development of triclosan and antibiotic resistance in Salmonella enterica serovar Typhimurium. J. Med. Microbiol. 58, 436-441 (2009).

2 Rybak, J. M. \& Grath, M. J. B. Combination antimicrobial therapy for bacterial infections, Guidelines for the Clinician. Drugs 52, 390-402 (1996).

3 Rishi, P., Mavi, S. K., Bharrhan, S., Shukla, G. \& Tewari, R. Protective efficacy of probiotics alone or in conjunction with a prebiotic in Salmonella-induced liver damage. FEMS. Microbiol. Ecol. 69, 222-230 (2009)

4 Bergonzelli, G. E., Blum, S., Brussow, H. \& Theulaz, C. I. Probiotics as a treatment strategy for gastrointestinal diseases. Digestion 72, 57-68 (2005).

5 Zou, J., Dong, J. \& Yu, X. Meta-analysis: lactobacillus containing quadruple therapy versus standard triple first-line therapy for Helicobacter pylori eradication. Helicobacter 14, 97-107 (2009).

6 Rishi, P., Preet, S. \& Kaur, P. Effect of L. plantarum cell-free extract and co-trimoxazole against Salmonella Typhimurium: a possible adjunct therapy. Ann. Clin. Microbiol Antimicrob. 10, 9 (2011)

7 Bauer, A. W., Kirby, W. M., Sherris, J. C. \& Turck, M. Antibiotic susceptibility testing by a standardized single disk method. Am. J. Clin. Pathol. 45, 493-496 (1966).

8 Tagg, J. R. \& McGiven, A. R. Assay system for bacteriocins. Appl. Microbiol. 21, 943-948 (1971). 
9 Ogunbanwo, S. T., Sanni, A. I. \& Onilude, A. A. Characterization of bacteriocin produced by Lactobacillus plantarum F1 and Lactobacillus brevisOG1. Afr. J. Biotechnol. 2, 219-227 (2003).

10 Clinical and Laboratory Standards Institute. M100-S20. Performance Standards for Antimicrobial Susceptibility Testing: 20th Informational Supplement, Clinical and Laboratory Standards Institute, Wayne, PA, USA, 2010.

11 White, R. L., Burgess, D. S., Manduru, M. \& Bosso, J. A. Comparison of three different in vitro methods of detecting synergy: time-kill, checkerboard, and $\mathrm{E}$ test. Antimicrob. Agents. Chemother. 40, 1914-1918 (1996).

12 Mandal, S., Mandal, M. D. \& Pal, N. K. Synergism of ciprofloxacin and trimethoprim against salmonella enterica serovar typhi isolates showing reduced susceptibility to ciprofloxacin. Chemotherapy 50, 152-154 (2004).

13 Aarestrup, F. M., Wiuff, C., Molbak, K. \& Threlfall, E. J. Is it time to change fluoroquinolone breakpoints for Salmonella spp.? Antimicrob. Agents. Chemother. 47, 827-829 (2003).

14 Threlfall, E. J., Skinner, J. A. \& Ward, L. R. Detection of decreased in vitro susceptibility to ciprofloxacin in Salmonella enterica serotypes typhi and paratyphi A. J. Antimicrob. Chemother. 48, 740-741 (2001).

15 Gutman, L., Al-obeid, S., Billot-klein, D., Guerrier, M. L. \& Collatz, E. Synergy and resistance to synergy between $\beta$-lactam antibiotics and glycopeptide resistant strains of Enterococcus faecium. Antimicrob. Agents. Chemother. 38, 824-829 (1994).

16 Botes, M., Loos, B., van Reenen, C. A. \& Dicks, L. M. Adhesion of the probiotic strains Enterococcus mundtii ST4SA and Lactobacillus plantarum 423 to Caco-2 cells under conditions simulating the intestinal tract, and in the presence of antibiotics and antiinflammatory medicaments. Arch. Microbiol. 190, 573-584 (2008).

17 Asahara, T. Nomoto, K. Shimizu, K. Watanuki, M. \& Tanaka, R. Increased resistance of mice to Salmonelaa enterica serovar Typhimurium infection by symbiotic administration of Bifidobacteria and transgalactosylated oligosaccharides. J. Appl. Microb. 91, 985-996 (2001).

18 Gonza'lez, B. et al. Bactericidal mode of action of plantaricin C. Appl. Environ. Microbiol. 62, 2701-2709 (1996).

19 Campos, M. A., Morey, P. \& Bengoechea, J. A. Quinolones sensitize Gram- negative bacteria to antimicrobial peptides. Antimicrob. Agents. Chemother. 50, 2361-2367 (2006).

20 Labro, M. T. Interference of antibacterial agents with phagocyte functions: immunomodulation or immuno-fairy tales. Clin. Microbiol. Rev. 13, 615-650 (2000).

21 Hatcher, G. E. \& Lambrecht, R. S. Augmentation of macrophage phagocytic activity by cell-free extracts of selected lactic acid-producing bacteria. J. Dairy. Sci. 76, 2485-2492 (1993).

22 Vincenti, J. E. The influence of cell-free Lactobacillus rhamnosus GG supernatant on the phagocytic activity of macrophages. Bio. Horizons 3, 105-112 (2010).

23 Feld, L. et al. Selective pressure affects transfer and establishment of a Lactobacillus plantarum resistance plasmid in the gastrointestinal environment. J. Antimicrob. Chemother. 61, 845-852 (2008).

24 Snydman, D. R. The safety of probiotics. Clin Infect Dis. 46(Suppl 2), S104-S111 (2008). 